\title{
Medical and lay attitudes towards genetic screening and testing in Finland
}

\author{
Hanna Toiviainen ${ }^{*, 1}$, Piia Jallinoja ${ }^{2,3}$, Arja R Aro $^{3,4}$ and Elina Hemminki ${ }^{1}$
}

${ }^{1}$ National Research and Development Centre for Welfare and Health (STAKES), Health and Social Services, PO Box 220, 00531 Helsinki, Finland; ${ }^{2}$ Department of Sociology, University of Helsinki, Finland; ${ }^{3}$ Department of Epidemiology and Health Promotion, National Public Health Institute, Helsinki, Finland; ${ }^{4}$ Department of Public Health, Erasmus Medical Center, Rotterdam, The Netherlands

The purpose of this study was to compare physicians', midwives' and lay people's attitudes towards genetic screening and testing to find out whether medical education and experience influence attitudes of genetic screening and testing. The study was based on comparison of answers to joint questions in three different cross-sectional postal surveys between October 1996 and April 1998 in Finland. Target groups were physicians (study base $n=772$, response rate $74 \%$, including gynaecologists, paediatricians, general practitioners and clinical geneticists), midwives and public health nurses (collectively referred to as midwives in the following; $n=800$, response rate $79 \%)$, and lay people $(n=2000$, response rate $62 \%)$. Midwives were more worried about the consequences of genetic testing and stressed the autonomy of the customer more strongly than lay people did. Furthermore, professionals considered that lay peoples' expectations as regards to genetic testing are too high. Having more medical education was related to having less 'cannot say' and missing responses. Our results do not suggest that major conflicts about the direction of genetic testing and screening would arise in near future. However, different positions and interests should be considered. Reporting in public about new prospects and developments in medical genetics should pay more attention also to concerns for balancing promises and drawbacks.

European Journal of Human Genetics (2003) 11, 565-572. doi:10.1038/sj.ejhg.5201006

Keywords: professionals; physicians; midwives; lay people; attitudes; genetic screening; genetic testing

\section{Introduction}

Different actors in health care have varying education, experience and roles as regards genetic screening and testing. Education and experiences may be associated with attitudes and understanding, and may have implications for information provision and for clients' decision-making and participation in screening and testing.

One of the roles of medical practitioners is to introduce and launch new technology. Health care professionals are

*Correspondence: H Toiviainen, National Research and Development Centre for Welfare and Health (STAKES), Health and Social Services, PO Box 220, 00531 Helsinki, Finland. Tel: 35893967 2431; Fax 35893967 2227; E-mail: hanna.toiviainen@stakes.fi

Received 28 March 2002; revised 6 March 2003; accepted 11 March 2003 gatekeepers of medical technology, strongly influencing how and when such technology is used. For example, physicians' attitudes have implications for the introduction and continuation of genetic screening. ${ }^{1-2}$ In Finland, midwives and public health nurses do not make healthpolicy decisions, but they transfer medical knowledge to lay people by providing health education and by counselling clients. They also have a central role in maternity and prenatal care and in prenatal diagnosis, ${ }^{3}$ areas in which genetic screening and testing have been much discussed.

Most of the earlier studies on attitudes towards genetics, genetic screening or genetic testing have not been comparative but conducted either among physicians or among lay people. ${ }^{4-12}$ Usually, studies have not covered attitudes more widely but focused on one specific disease 
or problem..$^{5-12}$ We found only two studies comparing professionals' and lay people's attitudes, both from the early 1990s in England. One study ${ }^{13}$ compared the attitudes of professionals, relatives and other members of the public towards cystic fibrosis (CF) carrier screening. In that study, large support for screening was found both among professionals and among lay people although low knowledge of CF in the latter group. The second study ${ }^{14}$ compared attitudes of professionals and public towards developments in genetic testing in pregnancy and decision-making. In that study, genetic applications were found to evoke both positive and negative feelings among both professionals and lay people, but lay people were more negative.

It is important to compare on the one hand attitudes towards genetics between different professional groups and on the other hand between health care professionals and lay people. It is possible that in health care, in maternity care for example, contradictions and even conflict arise because of varying expectations and worries about genetic testing. Furthermore, in circumstances where the applications of genetic testing or screening are under negotiation, it is vital to understand the standpoints of all groups involved.

At the time of our study, genetic screening was not used in clinical practice in Finland. Earlier in the 1990s an antenatal screening programme for INCL, aspartylglucosaminuria (AGU) and fragile-X was experimented in maternity clinics. ${ }^{1}$ Genetic testing for colon and breast-ovarian cancer was performed among at-risk groups quite actively. The purpose of this article is to compare Finnish physicians', midwives' and lay people's attitudes towards genetic screening and testing to find out whether medical education and experience influence attitudes of genetic screening and testing.

\section{Materials and methods}

The study materials were collected from three different questionnaire surveys conducted among physicians, midwives and lay people in Finland.

In November 1996, questionnaires were mailed to gynaecologists and paediatricians, including both leading physicians (all professors of gynaecology and obstetrics and of paediatrics and all specialist head physicians of hospital obstetric and paediatric units, $n=122$ ) and a random sample of ordinary practitioners (gynaecologists, $n=176$; paediatricians, $n=208) .{ }^{15-16}$ Additionally, all clinical geneticists in Finland $(n=21)$ and a random sample of general practitioners $(n=245)$ were included. One reminder was mailed in January 1997. Overall, 561 (74\%) physicians answered.

In February 1998, questionnaires were mailed to a random sample of 400 midwives and 400 public health nurses (subsequently all of them are referred to as midwives). ${ }^{17}$ One reminder was mailed in April 1998. Overall, 646 midwives responded (81\%). Excluding the 75 midwives who returned an empty form with an explanation that they do not work or have never worked as a midwife or public health nurse in maternity care, left 571 midwives (79\%).

Between October 1996 and January 1997, questionnaires were mailed to a random sample of 2000 Finnish adults aged 16-65. ${ }^{18-19}$ After two reminders, 1240 (61\%) answered. In this comparative study, we excluded health professionals from the sample in order to have a pure lay sample. Also, those younger than 23 years old and older than 65 years old were excluded to make the sample comparable with the two professional surveys, leaving a final total of 1050 respondents.

The physician questionnaire contained multiple-choice and open-ended questions on prenatal and genetic screening (Appendix). Genetic screening was defined as screening a general population, and genetic testing as testing selected individuals because of, for example, their family history, for (1) a future disease or predisposition to a disease or characteristic, or (2) carrier status of a disease or characteristic. The midwife questionnaire was a modified version of the physician questionnaire, and included additional questions from the lay people survey. Lay people questionnaire included general questions on genetics, and questions specifically on prenatal diagnosis, genetic testing and abortion.

There were three joint questions for physicians and midwives, four joint questions for midwives and lay people, and one joint question for all groups. Professionals' opinions on genetic screening were studied with a hypothetical, future-oriented question (Question 1 in the Appendix), and their attitudes towards medical technology were measured by asking for levels of agreement with a provided statement (Question 2). Additionally, we listed different aspects related to genetic screening and asked physicians to choose those about which they especially would like to educate lay people (Question 3). Midwives' and lay people's attitudes towards genetic testing during pregnancy were explored with an example case of parents declining a recommended genetic test (Question 4), and their attitudes towards genetic tests and disability were measured in terms of agreement with provided statements (Questions 5-7). The interest of all respondents in knowing their own risks for hereditary diseases was investigated by asking them to estimate the possibility that they would participate in a genetic test (Question 8).

Statistical testing of differences between the groups was performed using the $\chi^{2}$ test. In comparisons, the group having most medical education was chosen for the reference group. Since all midwives except one were women (Table 1), we also compared midwives to female physicians and lay women. 
Table 1 Respondents' background characteristics (\%)

\begin{tabular}{lccc}
\hline & Physicians $(\mathrm{n}=561)$ & Midwives $(\mathrm{n}=571)$ & Lay people $(\mathrm{n}=1050)$ \\
\hline Works in health care & 96 & $76^{* * *}$ & 0 \\
Education & & & \\
$\quad$ High & & 0 & 9 \\
Middle & 100 & 100 & 26 \\
Low & 0 & 0 & 18 \\
No information & 0 & 0 & $100^{\mathrm{b}}$ \\
All & 00 & 100 & $51 \mathrm{NS}$ \\
Women & 100 & $99^{* * *}$ & 5 \\
\hline
\end{tabular}

${ }^{a}$ High=university degree, middle=lower or higher vocational school, low=no degree after the basic education.

'In testing distribution, midwives and lay people were tested against physicians, and 'no information' group was excluded. $* * * P<0.001, N S=$ not statistically significant.

Table 2 Proportions of physicians $(n=561)$ and midwives $(n=571)$ who were in favour of genetic screening (\%) (Appendix, Question 1)

\begin{tabular}{|c|c|c|c|c|c|c|c|}
\hline & \multicolumn{2}{|c|}{ Screening for some target group } & \multicolumn{2}{|c|}{ Testing only } & \multicolumn{2}{|c|}{ Neither screening nor testing ${ }^{a}$} & \multirow[b]{2}{*}{ P-value } \\
\hline & Phy. & Mid. & Phy. & Mid. & Phy. & Mid. & \\
\hline Breast cancer & 45 & 42 & 36 & 34 & 14 & 15 & NS \\
\hline Familial hypercholesterolaemia & 40 & 28 & 47 & 44 & 9 & 17 & $* * *$ \\
\hline Juvenile diabetes & 39 & 40 & 36 & 37 & 20 & 13 & * \\
\hline Colon cancer & 35 & 30 & 47 & 42 & 13 & 16 & NS \\
\hline Adult-onset diabetes & 28 & 25 & 34 & 39 & 32 & 25 & * \\
\hline Huntington's disease & 19 & 14 & 49 & 47 & 21 & 16 & NS \\
\hline Schizophrenia & 18 & 13 & 28 & 39 & 47 & 36 & $* * *$ \\
\hline
\end{tabular}

a`No information' group is not shown. In testing distributions, midwives were tested against physicians, and 'no information' groups were excluded. ${ }^{*} P<0.05,{ }^{* * *} P<0.001, \mathrm{NS}=$ not statistically significant.

\section{Results}

Table 1 describes the respondents' background characteristics. The mean age of physicians was 47 years ( $\min 32$ and $\max 65$ ), that of midwives 41 years ( $\min 23$ and $\max 58$ ) and that of lay people 43 years (min 23 and max 65).

\section{Physicians and midwives}

Both physicians and midwives were more inclined towards selective genetic testing rather than screening the general population, with the exception of screening for breast cancer and juvenile diabetes (Table 2). More physicians than midwives wanted to screen for predisposition to familial hypercholesterolaemia, but more were of the opinion that neither screening nor testing should be done as regards to juvenile diabetes, adult-onset diabetes and schizophrenia. Furthermore, there were more midwives than physicians who did not answer these questions.

When asked, whether they thought it is probable that during the next 10 years will take part in a genetic test, only a minority of physicians and midwives said that they will probably take part (Table 3 ). Physicians more often than midwives regarded that it is unlikely.
The majority of both physicians and midwives considered lay people's expectations of medical technology to be too high (Table 4). Female physicians answered in the same way as all physicians.

\section{Professionals and lay people}

Responses to the example case of parents declining a recommended genetic test showed that both midwives and lay people valued parents' autonomy, but more midwives than lay people did so and midwives also more often than lay people were tolerant and understanding towards the couple's decision not to take the suggested gene test (Table 5). However, when asked about their personal choices in a corresponding situation, midwives' responses resembled those of lay people. Lay women's and men's answers were relatively similar.

Midwives less often than lay people were of the opinion that with genetic tests one may increase people's control over their lives and more often worried that genetic testing may lead to eugenics (Table 6). In other words, it seems that there was more optimism among lay people and more scepticism among midwives. 
Table 3 Distribution of respondents by their estimation that they will participate in a genetic test within the next 10 years (\%) (Appendix, Question 8)

\begin{tabular}{lccc}
\hline & Physicians $(\mathrm{n}=561)$ & Midwives $(\mathrm{n}=571)$ & Lay people $(\mathrm{n}=1050)$ \\
\hline Probably & 16 & 19 & 10 \\
Unlikely & 72 & 62 & 49 \\
Cannot say & 11 & 14 & 39 \\
No information & 1 & 5 & 2 \\
All & 100 & $100^{*}$ & $100^{\star * *}$ \\
\hline
\end{tabular}

Midwives and lay people were tested against physicians, and 'no information' groups were excluded. ${ }^{*} P<0.05$, $* * * P<0.001$

Table 4 Physicians' and midwives' opinions of lay-people's expectations (\%) (Appendix, Question 2)

\begin{tabular}{lcc}
\hline & Physicians ( $\mathrm{n}=561)$ & Midwives ( $\mathrm{n}=571)$ \\
\hline The public's expectations of medical technology are too high & & 62 \\
Agree & 76 & 19 \\
Disagree & 16 & 12 \\
Cannot say & 7 & 7 \\
No information & 1 & $100^{\star * *}$ \\
All & 100 & \\
\hline
\end{tabular}

In testing distribution, midwives were tested against physicians, and 'no information' groups were excluded. ${ }^{* \star * P<0.001}$.

Table 5 Distribution of midwives' and lay people's answers in the example case of parents declining a recommended genetic test $(\%)^{\mathrm{a}}($ Appendix, Question 4$)$

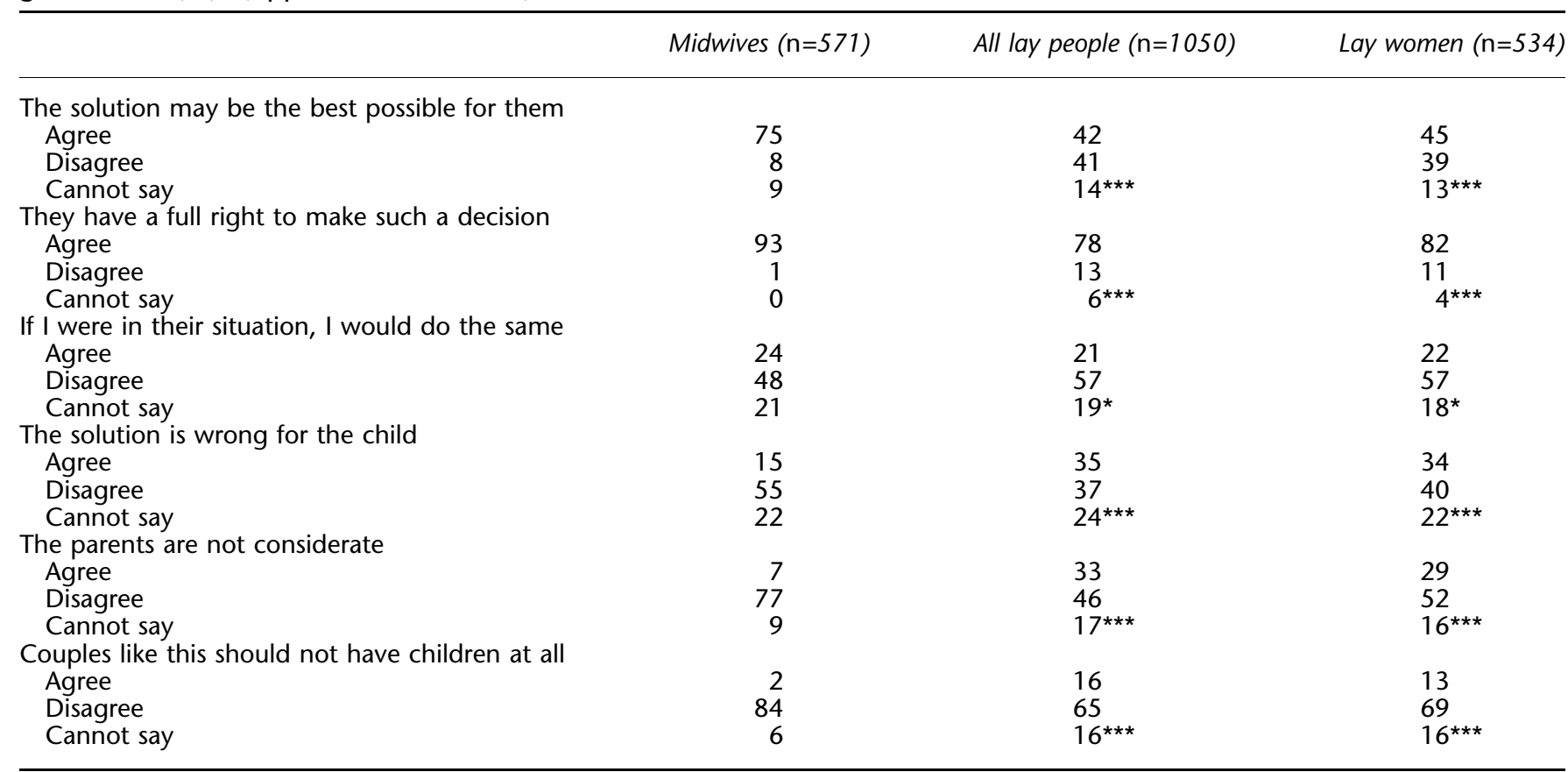

${ }^{a}$ NNo information' (2-8\%) group is not shown. In testing distributions, lay people and lay women were tested against midwives, and 'no information' groups were excluded. ${ }^{*} P<0.05,{ }^{* * *} P<0.001$.

Furthermore, midwives less often chose the 'don't know' option than did lay people.

When asked, whether it is probable that they will during the next 10 years will take part in a genetic test, there was a clear difference between the professionals and lay people in the certainty of the estimation; about $40 \%$ of lay people did not estimate this probability compared to just over $12 \%$ of professionals (Table 3 ). If only those expressing an estimation (ie excluding 'don't know' and no information) were considered, $18 \%$ of physicians, $23 \%$ of midwives and 
Table 6 Midwives' and lay people's attitudes towards genetic tests and disability (\%) (Appendix, Questions 5-7)

\begin{tabular}{|c|c|c|c|}
\hline & $\begin{array}{l}\text { Midwives } \\
(\mathrm{n}=571)\end{array}$ & $\begin{array}{l}\text { All lay people } \\
(\mathrm{n}=1050)\end{array}$ & $\begin{array}{l}\text { Lay women } \\
(\mathrm{n}=534)\end{array}$ \\
\hline \multicolumn{4}{|c|}{ With genetic tests one may increase people's control over their lives } \\
\hline Disagree & 39 & 13 & 15 \\
\hline Cannot say & 10 & $21^{\star * *}$ & $18^{\star * *}$ \\
\hline \multicolumn{4}{|c|}{ To have a disabled child is a disaster for the family } \\
\hline Agree & 17 & 31 & 28 \\
\hline \multicolumn{4}{|c|}{ I am worried that genetic tests may lead to eugenics } \\
\hline Agree & 68 & 51 & 57 \\
\hline Disagree & 22 & 31 & 27 \\
\hline Cannot say & 4 & $15^{\star \star \star}$ & $13^{* * *}$ \\
\hline
\end{tabular}

In testing distributions, lay people and lay women were tested against midwives, and 'no information' groups were excluded. ${ }^{\star \star \star} P<0.001$.

$17 \%$ of lay people said it is probable that they will participate in a genetic test.

Physicians wanted to educate lay people about the aspects related to genetic screening as follows: sensitivity and specifity of screening (false negatives and positives) (65\% of the physicians), concepts of risks and probability (64\%), clinical picture of the screened disease (49\%), advantages of knowing one's own prospects (40\%), influence of heredity and the environment on health (36\%), ethical consequences of genetic screenings (35\%), disadvantages of knowing one's own prospects (30\%), social consequences of genetic screening (21\%), consequences of screening and findings for health care resources (10\%).

\section{Discussion}

In summary, our results suggest that although in many respect physicians', midwives' and lay people's attitudes resemble each other, there are also significant differences. First, midwives were more worried about the consequences of genetic testing and stressed the autonomy of the customer more strongly than lay people did. Second, having more medical education was also related to having less 'cannot say' and missing responses.

The two professional surveys were planned to be comparative, but the lay-person survey was independent. However, the midwife questionnaire was made after the lay survey, and some joint questions were used. Professionals' response rates were high, but lay people's response rate only moderate. The midwife survey was made 16 months later than the other two surveys. During those 16 months no major breakthroughs or public discussion of genetic screening or testing occurred in Finland. A research screening of diabetes susceptibility among newborns was started, but it was not much discussed. Hence, it is unlikely that differences in attitudes between the groups studied could be explained as a reaction to public disputes or major changes in the way medical genetic is applied in health care.

In a study by Michie et $a^{14}$ in England in early 1990s lay people had more negative attitudes towards genetic applications than the professional groups. In our study, the opposite result was found. Previously, Finnish lay people's critical attitudes towards genetic testing have been found to be associated with higher education level and higher socio-economic status, ${ }^{18,20-21}$ and better knowledge about basic genetics has been found to be related to both more enthusiasm and more scepticism. ${ }^{19}$ Comparisons between countries, however, are difficult; differences in attitudes between countries may be explained by different traditions of reliance on medical specialists and lack of critical debate and dialogue. ${ }^{22}$

It has been previously found that Finnish women have a more critical attitude towards genetic tests than men. ${ }^{21}$ Analysis by gender showed that the differences between our study populations were not because of all midwives having been women.

In a study by Friedman et $a^{23}$ in 1996 in Texas, a minority of primary care physicians reported ever having referred a patient for a genetic evaluation for cancer risk. In our study, the proportions of physicians and midwives supporting hypothetical screening were smaller than in that study. In some studies carried out in the 1990s in the USA, both patients, members of at-risk families and the general public have been very interested in genetic testing for cancers of the breast, ${ }^{5}$ of the breast and ovaries, ${ }^{11-12}$ and of the colon, ${ }^{6}$ even though lower willingness to participate has been reported in other studies. ${ }^{8-9}$ In a Finnish study by Hietala et $a l^{24}$ both the public in general as well as family members of AGU (aspartylglucosaminuria) patients had favourable attitudes towards genetic tests and wide offering of the tests was accepted.

In our study, a majority of professionals and lay people said that it is unlikely that they would participate in a genetic test in the near future. Indeed, since the mid-1990s 
there has been only a few genetic screening or testing programmes in Finland, and thus the actual likelihood to participate in one is quite small. However, we should bear in mind that in these few programmes (genetic screening in maternity centre, neonatal diabetes screening, genetic cascade screening in cancer families) the uptake rate has been quite high, that is, $80-90 \%{ }^{25-26}$ and susceptibility testing for common diseases is expected to become the main type of test in the near future. ${ }^{27}$ Hence, despite the result that most respondents in all groups considered it improbable to uptake a gene test, genetic testing is steadily increasing in health care.

Regarding genetic testing during pregnancy, midwives were permissive toward parents' autonomy, and accepted the solution to decline the suggested gene test more often than did lay people. Midwives' attitudes are probably because of the professional norms emphasising nondirectiveness in genetic counselling - a norm that has been strongly emphasised in respect of genetic testing and prenatal diagnostics during the 1990s. However, it is important to note that although midwives were tolerant as regards to other people's decisions, only a minority of them would themselves decline the suggested gene test. In respect of own choices midwives resembled lay people.

We found out that lay people are more tended to choose 'don't know' responses than the professional groups. Turner and Michael $^{28}$ have argued that 'cannot say' responses to a knowledge and attitudes questions have different meanings, including real ignorance, unwillingness to answer, professional knowledgeable and ambivalent attitude or a potent political statement (deliberate choice not to answer). It is also a cultural phenomenon varying, for example, between countries. Turner and Michael continue that in science 'cannot say' responses can be employed by people to express their identity through their relationship with the ambivalent role of science. Currently, medical genetics is an area where development is rapid and where there are great variations in tests specifics and their implications. This situation may cause uncertainty among some individuals.

In our study, one of the key differences between the groups was the varying degrees to which the 'cannot say' option was used; midwives compared to physicians, and lay people compared to midwives gave more 'cannot say' and missing responses. It is possible that different groups with different medical education and experience understood the questions differently. However, it is not necessarily solely a question about knowledge but a qualitative difference between health care professionals' and lay people's attitudes; the first express professional opinions and the latter express personal thoughts. According to Skelton and Croyle, ${ }^{29}$ professionals use information which is not available to nonexperts, or use different decisionmaking rules. Furthermore, Croyle and Jemmott ${ }^{30}$ have argued that physicians' opinions, unlike lay people's, are not connected to personal health history. It is noteworthy that in the question concerning personal choices about genetic testing during pregnancy, midwives chose the 'cannot say' option as often as did lay people. The topic became more difficult as it became more salient and it was not possible to appeal so professional opinions and standards.

There were some differences between midwives and physicians as regards to attitudes towards testing and screening of various diseases. These differences, however, do not suggest that major conflicts about the direction of genetic testing and screening would arise in near future. Still, midwives' or other groups' possible concerns over genetic testing should be listened to in health care. Furthermore, we were satisfied to see that midwives took the principle of health care consumers' autonomy seriously. Other studies have shown that lay people indeed are of the opinion that gene tests should be voluntary and a private matter. ${ }^{19}$ However, further research is needed to examine whether the principle of autonomy is actualised in genetic counselling.

Our study indicates that lay people's expectations as regards to genetic testing are too high - at least this is how the professionals under study here saw the situation. We suggest that in the future, when reporting in public about medical genetics, both new prospects and developments as well as drawbacks and delays (temporal, financial, attitudinal) should be considered. For example, the introduction of genetic screenings in Finnish health care has not been as rapid as was expected among the geneticists' community in the early 1990s. ${ }^{31}$ It might be that the early enthusiasm among the physicians themselves is reflected in lay people's more straightforward attitudes. For balancing the promises and drawbacks of new genetics, media as well as health professionals and researchers are important actors.

\section{Acknowledgements \\ This study resulted from an EU-BIOMED2 project entitled 'The development of prenatal screening in Europe: The past, the present, and the future', EU contract no. BMH4-CT96-0740. ${ }^{32}$ The study was funded by the European Union, the National Research and Develop- ment Centre for Welfare and Health, and the Academy of Finland. There are no financial or other conflicts of interest because of funding. We thank the members of the EU group for their help in constructing the questionnaire, and Dorothy $C$ Wertz and John C Fletcher for the question concerning genetic testing during pregnancy, modified as Question 5 in the Appendix A: Wertz DC, Fletcher JC. Ethics and Genetics. An international survey. A questionnaire.}

\section{References}

1 Jallinoja P: Genetic screening in maternity care: preventive aims and voluntary choices. Soc Health Ill 2001; 23: 286-307.

2 Santalahti P, Hemminki E: Use of prenatal screening tests in Finland. Eur I Public Health 1998; 8: 8-14. 
3 Hemminki E, Gissler M: Quality and targetting of antenatal care in Finland. Acta Obstet Gynecol Scan 1993; 72: 24-30.

4 Hietala M, Hakonen A, Aro AR, Niemelä P, Peltonen L, Aula P: Attitudes toward genetic testing among the general population and relatives of patients with a severe genetic disease: a survey from Finland. Am J Hum Genet 1995; 56: 1493-1500.

5 Chaliki H, Loader S, Levenkron JC, Logan-Young W, Hall J, Rowley PT: Women's receptivity to testing for a genetic susceptibility for breast cancer. Am J Public Health 1995; 85: 1133-1135.

6 Smith KR, Croyle RT: Attitudes toward genetic testing for colon cancer risk. Am J Public Health 1995; 85: 1435-1438.

7 Benkendorf JL, Reutenauer JE, Hughes CA et al: Patients' attitudes about autonomy and confidentiality in genetic testing for breastovarian cancer susceptibility. Am J Med Genet 1997; 73: 296-303.

8 Lerman C, Narod S, Schulman K et al: BRCA1 testing in families with hereditary breast-ovarian cancer. A prospective study of patient decision making and outcames. JAMA 1996; 275: 18851892.

9 Patenaude AF, Basili L, Fairclough DL, Li FP: Attitudes of 47 mothers of pediatric oncology patients toward genetic testing for cancer predisposition. J Clin Oncol 1996; 14: 415-421.

10 Lerman C, Seay J, Balshem A, Audrain J: Interest in genetic test among first-degree relatives of breast cancer patients. Am J Med Genet 1995; 57: 385-392.

11 Struewing JP, Lerman C, Kase RG, Giambarresi TR, Tucker MA: Anticipated uptake and impact of genetic testing in hereditary breast and ovarian cancer families. Cancer Epidem Biomar 1995; 4: 169-173.

12 Lerman C, Daly M, Masny A, Balshem A: Attitudes about genetic testing for breast-ovarian cancer susceptibility. J Clin Oncol 1994; 12: 843-850.

13 Watson EK, Williamson R, Chapple J: Attitudes to carrier screening for cystic fibrosis: a survey of health care professionals, relatives of sufferers and other members of the public. Br J Gen Pract 1991; 41: 237-240.

14 Michie S, Drake H, Bobrow M, Marteau T: A comparison of public and professionals' attitudes towards genetic developments. Public Underst Sci 1995; 4: 243-253.

15 Toiviainen H, Hemminki E: Finnish physicians' interest in genetic screening. Community Genet 2001; 4: 27-35.

16 Hemminki E, Toiviainen H, Santalahti P: Views of Finnish doctors on fetal screening. Br J Obstet Gynecol 2000; 107: 656-662.

17 Jallinoja P, Santalahti P, Toiviainen H, Hemminki E: Acceptance of screening and abortions for Down's syndrome among Finnish midwives and public health nurses. Prenatal Diag 1999; 19: 10151022

18 Jallinoja P, Aro AR: Knowledge about genes and heredity among Finns. N Genet Soc 1999; 18: 101-110.

19 Jallinoja P, Aro AR: Does knowledge make a difference? The association between knowledge about genes and attitudes towards gene tests. J Health Commun 2000; 5: 29-39.
20 Aro AR, Hakonen A, Hietala M et al: Acceptance of genetic testing in a general population: age, education and gender differences. Patient Educ Couns 1997; 32: 41-49.

21 Aula P, Hietala M, Niemelä P et al: Miten suomalaiset suhtautuvat geenitesteihin. Duodecim 1996; 112: 95-102 (The Finnish attitudes towards gene tests)

22 Miettinen R, Väliverronen E: In science we trust: on the public understanding of science in Finland; in Miettinen R (ed): Biotechnology and public understanding of science. Helsinki: Academy of Finland, 1999.

23 Friedman LC, Plon SE, Cooper HP, Weinberg AD: Cancer genetics - Survey of primary care physicians' attitudes and practices. $I$ Cancer Educ 1997; 12: 199-203.

24 Hietala M, Hakonen A, Aro AR et al: Attitudes towards genetic testing among the general population and relatives of patients with a severe genetic disease: a survey from Finland. Am J Hum Genet 1995; 56: 1493-1500.

25 Aro AR, Jallinoja P: Prenatal genetic screening: the Finnish experience; in Ettorre E (ed): Before birth. Understanding prenatal screening. England \& USA: Ashgate, 2001, pp 143-155.

26 Hietala M, Aula P, Syvänen AC et al: DNA-based carrier screening in primary healthcare: screening for aspartylglucosaminuria mutations in maternity health offices. Clin Chem 1996; 42: 1398-1404.

27 Bell J: The new genetics in clinical practice. BMJ 1998; 316: 618620.

28 Turner Jill, Michael Mike: What do we know about "don't knows"? Or, contexts of "ignorance". Soc Sci Inform 1996; 35: 15-37.

29 Skelton JA, Croyle RT: Mental representation, health and illness: an introduction; in Skelton JA, Croyle RT (eds): Mental representation in health and illness. New York: Springer-Verlag, 1991, pp 1-9.

30 Croyle RT, Jemmott JB: Psychological reactions to risk factor testing; in Skelton JA, Croyle RT (eds): Mental representation in health and illness. New York: Springer-Verlag, 1991, pp 85-107.

31 Jallinoja P: Genetics, negotiated ethics and the ambiguities of moral choices. Helsinki: Publications of the National Public Health Institute A2, 2002.

32 Prenatal screening in Europe: the past, the present and the future. Final report, EU contract no. BMH4-CT96-0740.

\section{Appendix: Questions}

\section{Physicians and midwives}

Question 1. If it becomes technically possible to genetically screen for the following diseases and/or for the predisposition to them, for which diseases and for whom would it be good to be screen? (you may circle many)

Nobody $\begin{gathered}\text { Only on the } \\ \text { grounds of } \\ \text { family history }\end{gathered}$

1. Juvenile diabetes (Type I)........

2. Adult-onset diabetes (Type II)

3. Familial hypercholesterolaemia

4. Schizophrenia

5 . Finnish heritage diseases.

6. Breast cancer (women).............

7. Colon cancer

8. Huntington's disease........... family history

$\begin{array}{ccccc}\begin{array}{c}\text { The whole } \\ \text { population }\end{array} & \text { Fetuses } & \text { Newborns } & \begin{array}{c}\text { School } \\ \text { pupils }\end{array} & \begin{array}{c}\text { Men in } \\ \text { military } \\ \text { service }\end{array} \\ 3 & 4 & 5 & 6 & 7 \\ 3 & 4 & 5 & 6 & 7 \\ 3 & 4 & 5 & 6 & 7 \\ 3 & 4 & 5 & 6 & 7 \\ 3 & 4 & 5 & 6 & 7 \\ 3 & 4 & 5 & 6 & 7 \\ 3 & 4 & 5 & 6 & 7 \\ 3 & 4 & 5 & 6 & \end{array}$

Respondents were classified as supporters of screening if screening was suggested for any of the target groups. 


\section{Question 2.}

The public's expectations of medical technology are too high

In the data the options 'Completely agree' and 'Agree' were combined into a category 'Agree' and the options 'Completely disagree' and 'Disagree' into a category 'Disagree'.

Question 3. Which of the following aspects related to genetic screening you would especially like to educate lay people about ? (you may circle many)

1. Sensitivity and specifity of screening (false negatives and positives)

2. Concepts of risks and probability

3. Clinical picture of the screened disease

4. Consequences of screening and findings for health care resources

5. Influence of heredity and the environment on health

6. Advantages of knowing one's own prospects

7. Disadvantages of knowing one's own prospects

8. Social consequences of genetic screening

9. Ethical consequences of genetic screening

10. Other, what?

\section{Midwives and lay people}

Question 4. Let's consider a situation in which a couple has a 25\% probability to have a severely mentally retarded child. The woman is now three months pregnant. However, the couple refuses to take part in the genetic test their doctor suggests. What do you think about the situation?

To have a disabled child is a disaster for the family
1. The solution may be the best possible for them

2. They have a full right to make such a decision

3. If I were in their situation, I would do the same

4. The solution is wrong for the child

5. The parents are not considerate

6 . Couples like this should not have children at all

Question 5.

With genetic tests one may increase people's control over their lives

Question 6.

Question 7.

I am worried that genetic tests may lead to eugenics

$\begin{array}{ccccc}\begin{array}{c}\text { Completely } \\ \text { agree }\end{array} & \text { Agree } & \text { Disagree } & \begin{array}{c}\text { Completely } \\ \text { Disagree }\end{array} & \text { Cannot say } \\ 1 & 2 & 3 & 4 & 5 \\ 1 & 2 & 3 & 4 & 5 \\ 1 & 2 & 3 & 4 & 5 \\ 1 & 2 & 3 & 4 & 5 \\ 1 & 2 & 3 & 4 & 5 \\ 1 & 2 & 3 & 4 & \text { Cannot say } \\ \begin{array}{c}\text { Completely } \\ \text { agree } \\ 1\end{array} & \text { Agree } & \text { Disagree } & \begin{array}{c}\text { Completely } \\ \text { disagree }\end{array} \\ \begin{array}{c}\text { Completely } \\ \text { agree }\end{array} & \text { Agree } & \text { Disagree } & \begin{array}{c}\text { Completely } \\ \text { disagree }\end{array} & \text { Cannot say } \\ \begin{array}{c}\text { Completely } \\ \text { agree }\end{array} & \text { Agree } & \text { Disagree } & \begin{array}{c}\text { Completely } \\ \text { disagree }\end{array} & \text { Cannot say } \\ 1 & 2 & 3 & 4 & 5\end{array}$

In the data the options 'Completely agree' and 'Agree' were combined into a category 'Agree' and the options 'Completely disagree' and 'Disagree' into a category 'Disagree'.

\section{All groups}

Question 8. Do you think that during the next 10 years, you will take part in a genetic test?

1. Very probably

2. Quite probably

3. Quite unlikely

4. Very unlikely

5. Cannot say

In the data the options 'Very probably' and 'Quite probably' were combined into a category 'Probably' and the options 'Very unlikely' and 'Quite unlikely' into a category 'Unlikely'. 